\title{
COMPUTER INTEGRATED ENTERPRISE IN THE MRP/ERP SOFTWARE IMPLEMENTATION
}

\author{
Andrzej KAMIŃSKI \\ Faculty of Management \\ Warsaw University of Technology, 02-524 Warszawa, Poland \\ e-mail: a.kaminski@wz.pw.edu.pl
}

\begin{abstract}
The aim of this elaboration is to present selected methodology, application and design issues connected with the process of complex enterprise informatization in the implementation process of an IT system. Role of the integration process in economic information processing and directions of integration activities in the scope of the IT systems of the enterprise are presented in the first part of this elaboration. Afterwards, technical features of an integrated IT system are characterized. Thesis that particular systems are comparable in the scope of functionality of the basic areas of activity of the enterprise, such as: accounting, material and stock planning, sales and invoicing, human resources, wages, can be formulated on the basis of the national portfolio of ERP (Enterprise Recourses Planning) packages. On the other hand, the cost of license purchase as well as the implementation activities, reaches the level from tens of thousands to few million PLN. Differences in the levels of investments are determined with: scope and complexity of the endeavor, functionality and system architecture as well as the cost of extension and modification of provided program modules.
\end{abstract}

Key words: IT system, MRP, ERP, computer integrated enterprise, methodology of complex enterprise informatization program.

1

\section{Introduction}

The aim of this elaboration is to present selected methodology, application and design issues connected with the process of complex enterprise informatization in the implementation process of an IT system ${ }^{1}$.

Attempt of classification of the $\mathrm{ERP}^{2}$ software was made, with the differences $\mathrm{n}$ software architecture of various systems born in mind. Main classification

\footnotetext{
${ }^{1}$ ERP class system (Enterprise Resource Planning) is an integrated, highly effective, multi-access IT system - designed for the needs of complex management of manufacturing enterprise. ERP systems, subjected to continuous improvement and development, became the most common tools for production managing and planning is large and medium enterprises (70\% of computerized manufacturing enterprises in highly developed Western European countries is basing their business activities on MRP standard IT systems). ERP systems originate from the Material Requirements Planning standard elaborated in the seventies. Next generation - MRP II - was extended with sales processes elements as well as elements that support the decision making processes at the strategic production management level.

${ }^{2}$ Technical architecture of integrated ERP system includes four basic application software layers: user interface (collection of connected graphical forms that function in the environment of Windows, Web, Linux etc.), business applications (software modules and components elaborated by a team of analysts, designers and programmers from the provider of the integrated package), development and new application creation environment (administrative tools, form generators, report generators, code generators) and data resources (relational database, which records all economic operations).
}

criterion was the adaptation level of the system to the needs and specific character of selected industrial organization.

Methodology concept of complex enterprise informatization program, with special attention for analytical and design activities, is also presented in this elaboration. The aim of such activities is the substantial preparation of the industrial organization to the implementation of integrated and compliant with standards ERP system. This process is initiated by the elaboration of informatization strategy, followed by complete system analysis and the construction of system and software infrastructure.

Final effect is the restructuring (industrial conversion) of the enterprise through ERP package implementation, cost reduction, improvement of economic indicators and improvement of operational and managerial processes.

\section{Integration function in the process of industrial information processing}

Integration process is based on the connection of functional elements with relations in a way that they become part of a specific structural entity ([6], p 55). According to the definition, integration process is the activity or a sequential set of activities, which need to be performed in order to reach desired effect, e.g. 
joining two industrial enterprises - connection of functions, organizational structures, technological processes, pricing and product quality policies.

Relating the quoted definition to sciences form the scope of economics and enterprise management, professor E. Niedzielska introduces the concept of integrated management environment defined as "economic, technological and social micro-space of common endeavors (manufacturing, services, investment, distribution, marketing and other), which depend on complex (multi-module, multifunctional) integrated industrial IT systems of market partners - Business Information Systems" ([14], p. 45).

According to Gartner Group, from the perspective of informatization of the entirety of enterprises economic processes, integration is the "realization of large, complex IT projects that concern elaboration and/or creation of architectures and applications adjusted to specific customer requirements as well as integration with new or existing computer or telecommunication software and hardware". In this definition the crucial integration criterion are the size and complexity of the projects dealing with IT technology development (acc. to [13], p. 7).

On the other hand professor M. Bazewicz considers the IT system integration issues on technological, datalogical (concerns programs, data formats and structure, programming languages, facts and events description language) and infological (representation of the knowledge in the system) levels. He also proves that the most important condition of IT system cooperation is the semantics, which is the consistency of concepts used to describe sentences, facts, events. Successive consistency level is the unification of measures, norms and classification rules ([2], p. 103).

From the perspective of technological factors, integration is the "complete and compliant set of international technological standards and functional specification interfaces, services and formats to assure interefficiency and transferability of applications, data and human resources." ([5], p. 22). Integration issues of listed media in the IT systems, using multimedia technology, are described in the work [7].

Economic process integration is also an essential element of integration activities. Economic process integration is defined as identification, documentation and management of relations taking place between particular processes. The aim of these activities is to reach synergy effect, which means that all mutually connect- ed processes, organizational cells, information channels and control mechanisms are functioning optimally as a complex economic (entity) system ([19], p. 16). Integration of economic processes allows the control over information, material and energy flow beyond the boundaries of the enterprise, what is possible due to the connection of all necessary heterogenic functional units in order to improve communication, cooperation and coordination in given enterprise. Heterogenic functional units of the enterprise, which are to be integrated, are: IT systems, hardware, applications and human resources. As a result the enterprise functions as an entirety, increases global productivity, flexibility and change and innovation introduction.

Standardization of economic information flow system document forms is the basic condition for the information processing automation. As a result of content analysis of particular documents, it is necessary to determine the following: are there multiple documents reflecting the same economic event, is the data in different documents not repeated and whether there are differences of the description of particular economic events in various documents?

In order to allow electronic document transfer and exchange it is necessary to use determined recording format standardization. For example in the construction of WWW websites the standard document recording format is the HTML language (Hyper Text Markup Language). HTML language was elaborated on the basis of SGML meta-language (Standard Generalized Markup Language) ([18], pp. 183-198).

This technology allows publishing and presenting documents in the Internet, independent of presently used system and hardware platform. Alternative solution would be the usage of the commonly accepted text file format "txt". However, this format is used only to record the content of the document, whereas HTML allows transferring both the text and graphical content of the document. Document standardization methods, together with practical examples, are presented in the work ([4], pp. 12).

Enterprise model elaboration is the integral element of the integration activities. It is a multilevel, logical representation of the economical processes ([9], pp. 5571). Using special dedicated software (e.g. ARIS Toolset, Corporate Modeler) allows simulating organizational changes, process relation evaluation and flexible transferring of resources. 
Integration in manufacturing enterprises was the main premise CIM (Computer Aided Manufacturing), integration of ,automation islands" that were created as a result of rapid and intensive automation that took place in the seventies and the beginning of the eighties. CIM concept allows an effective usage of IT technologies as part of the computer production integration.

However, integration concerns also other parts of the enterprise, where the main goal is the "information islands" integration, connection of dedicated subsystems, data redundancy elimination through the creation of integrated database systems and multi-accessibility of the IT system through the creation of customerserver applications.

In the IT systems integration process it is important to consider two independent possibilities of integration activities: complete system integration - possible as a result of technological unification of functional modules, data structures, processing methods, programming tools, communication protocols and the occasional system integration - based on the elaboration of data exchange platform between independent domain subsystems.

First solution creates the possibility for full integration of transactional systems. The aim of this process is strive for the registration and processing of all economical operations in homogenous, both functionally and technologically, integrated system. For example in the finance and accounting department all processes connected with financial documents processing, starting from account plan unification and finishing with the elaboration of common activity procedures, will be subjected to integration processes. Implementation of complete enterprise IT system integration method in practice means high cost connected with purchasing of application software and modernization of the hardware infrastructure, relatively long time of the implementation and the necessity to perform organizational changes.

Second solution is the maintaining of decentralized transactional processing systems, creation of finance data consolidation and optimization according to analytical processing. Presented concept creates the basis for the creation of data warehouse, creation of multilevel data representation models - OLAP technology (On-Line Analytical Processing) as well as the imple- mentation of intelligent knowledge gathering - Data Mining tools.

From the perspective of CIM, integration issues concern the IT systems in the mother enterprise (internal integration). However, integration process can concern also the creation of relations between IT systems of different enterprises (external integration).

For example in the design of stock management aiding system designated for an enterprise that has regional and geographical agencies, dispersed architecture can be used in order to process operational data in realtime. Therefore, in case of a considerable customer order for products not available in stock of the local supplier, crucial factor being the delivery time, it is possible to realize the order due to the information about the stock levels of other agencies and partners.

At this stage the technological analysis of the system implementation aspects is not relevant. It is crucial to make a strategic assumption that the provision of information that is reliable and up-to-date, which is possible with transactional processing of dispersed economic information, is one of the key success factors. It is also possible to include suppliers into the system (Business to Business), in order to reduce the stock cost, in further perspective.

In another example - enterprise functioning in a holding structure, created of smaller capital-connected companies - the issue of data integration for the needs of current controlling and reporting should be approached differently. With the assumption that the Board expects weekly reports on the level of sales in particular companies and also periodical analytical reports for the capital group it is reasonable to create a data warehouse. In this case feeding the central data warehouse with data should be realized with, so called, lot and periodical method, using the data replication mechanisms offered by database servers. It is reasonable to consider publishing of some of the statistical data in the internet in further perspective.

The main requirement for the integrated system, in every described example, is the necessity to have updated operational data. Final user is not interested in the data integration method but rather in the fulfillment of certain formal requirements: up-to-date data and the standard inquiry response time of the system.

It is important to emphasize that there is a considerable difference between the transactional system operating in the online architecture and the analytical system fed 
in the lot and periodical regime. Proper evaluation of the real needs determines the selection of certain technical architecture of the system.

\section{Classification of integrated systems}

Integrated system consists of standard modules designated for the servicing of all data transfers that support the functioning of the industrial organization. Integrated system is designated for the computer aiding of economic operation processing at operational and managerial levels:

- operational level - employees benefit from process automation e.g. one time introduction of source documents to the system, possibility to gain access to the functions of the system that allow to realize certain tasks,

- managerial level - high management has the possibility to monitor the financial condition of the en- terprise, check the current product and raw material stock, planning of rational logistics, maintenance and action in case of irregularities.

It is essential to evaluate the possibility of adjustment of given package to the character of selected industrial organization, from the perspective of the complete business processes informatization concept. Therefore it is reasonable to elaborate the classification of integrated systems, with the evaluation of adaptive possibilities as a division criterion (see Figure 1).

Classification of integrated systems:

\section{Dedicated systems}

Dedicated systems are designed on the basis of full system analysis of the industrial enterprise. Technological tools of external software companies are used in the application software construction process.
Integrated IT systems of the enterprise

\section{Dedicated systems}

\section{Standard systems}

\section{Universal systems}

\section{Closed systems}

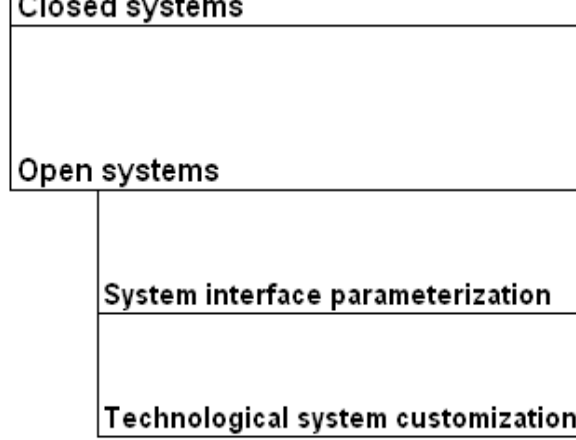

Branch systems

\section{Parame- terization scope very high \\ low \\ medium \\ Remarks \\ Systems designed on the basis of complete system analysis of the industrial organization. Tools from external software companies are used in the process application software design \\ Implementation process is a compromise between enterprise requirements and system functionality \\ Computer aiding of typical business processes (e.g. Sales, Financial Accounting, Stock Management) independent of the profile of enterprise activities}

low

medium

medium

high

medium

These systems are replicable and designed for servicing small and medium enterprises. They differentiate with low cost of application software, due to mass sales. Scope of modification is limited with the material indexes, file index definitions etc

Parametric systems that allow to adjust user system interface and creation of new functional modules

Scope of expectations and changes includes graphical interface structure modification and content of the generated reports

Systems equipped with integrated programming environment designated for the creation of modules servicing specific enterprise processes

Systems designated for servicing of particular industrial branches (e.g. electro-energetic branch)

Figure 1. Classification of integrated systems

$$
\text { (source: self study) }
$$




\section{$2 \quad$ Standard systems}

\subsection{Universal systems}

These systems include supporting of business processes (e.g. Sales, Controlling, Stock Management), independent of the company's profile. Universal systems include:

\subsubsection{Closed systems}

These systems are replicable and designed for servicing small and medium enterprises. They differentiate with low cost of application software, due to mass sales (in thousands of pieces). The main disadvantage of such systems is their low flexibility in adjusting to the needs of the enterprise. Scope of modification is limited with the material indexes, file index definitions etc.

\subsubsection{Open systems}

Systems that allow to adjust system's interface and create new functional modules. Open systems include:

- Open systems allowing modification of key functional parameters. Parameter is the variable, which after taking certain value (setting) triggers a specific action of a particular system module ([17], p. 352). Setting of some parameters should be treated as permanent (in a functioning system it is not advisable to change the parameters without previous consulting with the specialists). For example one of the parameters defined as "permanent" is the multi-serviceability (the possibility to simultaneously service the accounting of many enterprises) and the "variable" parameter can be the currency format (e.g. display of the currency with two digits after the coma).

- Open systems allowing modifying the user interface. User interface layer includes the graphical interface of the application, which is the normalized set of mutually connected forms, consistent for the whole package according to ergonomics of the steering elements placement (action buttons, options menu) as well the elements allowing the introduction, edition and modification of data (data labels, text fields, scroll-down lists). Scope of requirements and changes includes the modification of the graphical interface of the application and the informational content of generated reports. It is important to emphasize that the servicing of the report generator does not require any programming skills and is based only on discovering the character of particular tool and convention, in which the inquiry is constructed and the final layout of the re- port (printout) is determined. Modern reporting tools are equipped with visional environment of SQL inquiries in order to simplify the design process. Console of the system administrator is an integral system of the ERP package. Assigning authorization level for the particular functional modules or objects as well as the graduation of authorization level is performed with the administrator's console.

- Open systems allowing technological system customization. Such systems are equipped with integrated programming environment (application generators) designated for the creation of extensions of standard functionality of given package and creation of new modules, which would service the specific processes of the enterprise. One of the main features of the environment is the use of visional modeling tools for the user dialogue form, high automation level of standard programming activities and isolation form the system software layer (data transferring protocols, printout controlling, authorization control). It is crucial to point out that the integrated programming environment is not typical only for "higher-class" ERP systems. Currently this component is present in packages designated for small and medium enterprises.

For example the Navision Attain ${ }^{3}$ package is equipped with a set of tools for the creation and modification of particular layers of the software. Architecture of this package consists of three basic layers: presentation layer, design layer and code layer (see Figure 2).

First layer is the "Presentation layer". Graphical application interface consists of electronic forms collection, which is used by the users in daily system exploration. Forms in this layer are grouped in thematic structures (modules). Module is used to service the typical areas of the enterprise activities (e.g. Sales, Stock, HR -

\footnotetext{
${ }^{3}$ Microsoft Business Solutions - Navision is a family of ERP packages (Microsoft Business Solutions - Navision Attain and Microsoft Business Solutions Navision Standard), which were created by a Danish enterprise Navision Software, later intercepted by Microsoft, currently supported by the Microsoft Business Solutions department. Navision Attain is an integrated IT system, designated for medium enterprises. Navision consists of the following modules: main book, material assets, sales and debt, purchasing and liabilities, stock, orders, human resources wages, production. System allows multicurrency money transfers, selection of various languages of the user interface and usage of custom Navision Developers Kit programming tools. It works in the client-server environment using Windows NT/XP/VISTA and IBM AIX platforms. Microsoft Business Solutions - Navision Standard is a solution designated for small enterprises (up to 10 users).
} 
wages etc.). User does not have the possibility to interfere with the data objects'(text boxes, labels, scrolldown lists) structure displayed in particular forms and to change the content generated by the reporting system. General rule of dialogue boxes construction and data object grouping, graphical layer and user communication are consistent and ergonomically correct. Similarly, the set of inbuilt rules responsible for the correctness validation of inserted data as well as the navigational mechanism (system menu) and the control mechanism are uniform for the whole system.

Second layer is the "Design layer". This layer allows access to properties and settings of objects. These tools were hidden beneath the layer of electronic forms of the first layer. Integrated project environment shares the mechanisms necessary to create new forms and for the editing of the existing ones. Apart from the interference in the graphical layout of the form, adding new data objects and connecting them to the objects from the database, is also possible.

It is important to explain that the forms are only the representation of data stored in the tables. Therefore, design stage needs to connect the data objects in the form with relevant fields in the data tables.
The final (third) layer is the "Code layer". This layer allows constructing validation control mechanisms introduced by the user of the input data, creation of business rules and complex processing operations (e.g. the commission calculation mechanism for the salesman with relation to current sales results of products and services and historical data).

Designing and programming environment of the Navision Attain system allows isolating the IT technician - programmer from the table, field and relation creation mechanisms for particular database management systems. For example, "Design layer" allows performing operations connected with adding of attributes to existing data tables.

This operation is relatively simple and comes down to selection of the source table and inserting the name of new attribute together with the determination of its type. Programming and design environment automatically generates scripts in SQL language, which perform proper modifications in the database structure from the server side.

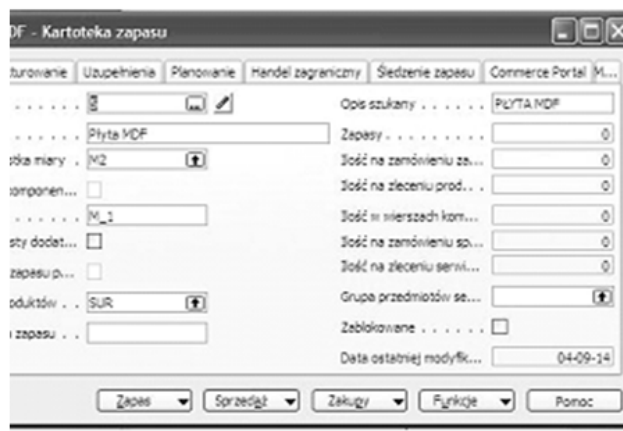

Standard system form

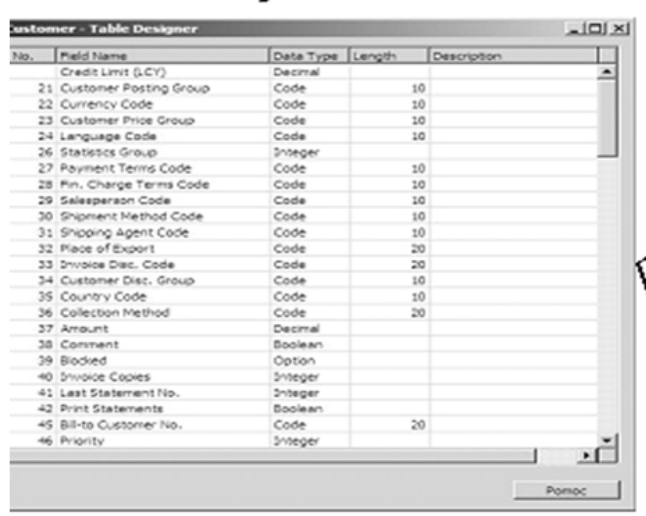

Data table editor

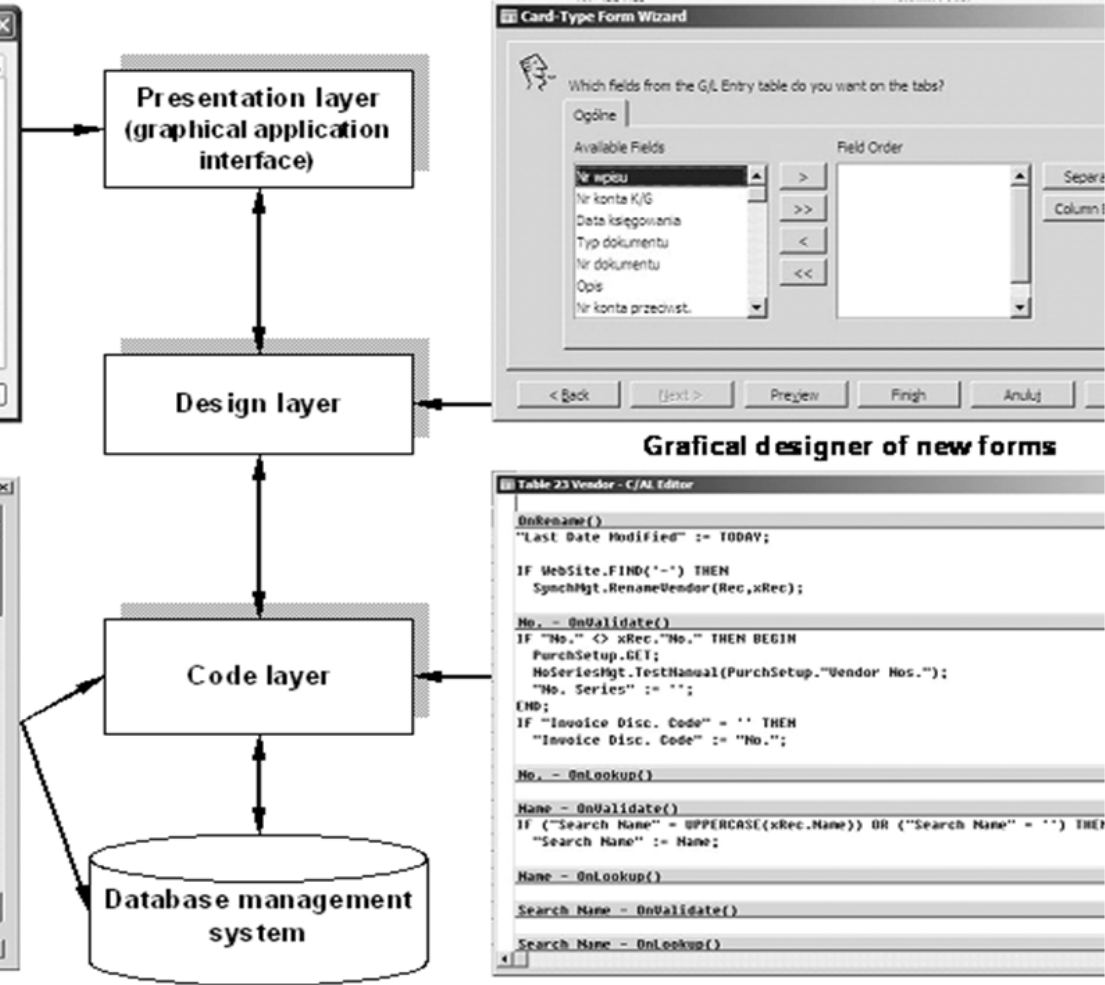

System code editor

Figure 2. Architecture of integrated IT system (source: self study) 


\subsection{Branch systems}

Branch systems are designated for the servicing of selected trade lines and industrial branches (e.g. energetic, chemical, textile industry) as well as custom enterprise activities profiles. This category of IT systems is characterized with a higher level of functional advancement than in case of universal systems - as a result of technological modifications of standard system modules and creation of new solutions, typical for particular industrial branch. For example the JBA Company provides branch solutions for manufacturers and distributors of food, beverages, clothing and shoes as well as the automotive industry ([1], p. 30).

In detailed approach:

- food system was created according to the requirements of food manufacturers and distributors, especially with relation to hygiene and quality; many companies are using the system e.g. bakeries, meat-processing industry,

- drinks system fulfills the requirements of manufacturers and distributors of alcoholic and nonalcoholic beverages, who need to obey strict technological regimes of fluid manufacturing and package material management,

- automotive system - version designed for the automotive industry.

Reference models are used In order to perform the comparison analysis and evaluation of the enterprise processes compliancy with representative solutions for particular branch. For example the ARIS-Toolset is provided with branch reference models, such as: automotive industry, furniture, paper. Branch reference models support the selection of standard software, because they can act as requirement specification with relation to particular business solution ([12], p. 209).

Summing up the deliberations above - implementation of branch systems is dedicated with the following technical and economical premises:

- cost of the branch system implementation is lower than the cost of universal package, it is easier to learn the basic functionality of the system for the final users as well as the need for the functional adaptation of the whole system and its communication media is lower,

- significant similarity of particular enterprises in selected branch is visible, what leads to the possibility of sales scale effect increase.

\section{Organization of the informatization process of the enterprise}

Design of the complex informatization process organization is the basic element of the technical and organizational project of the industrial conversion of the enterprise. The aim of this process is to: create stable hardware and system infrastructure, link exploited domain subsystems in the integrated system formula as well as, in further perspective, creation of industrial organization knowledge management system.

Stage 1 Elaboration of the industrial object informatization strategy

Strategy is a concept with many different meanings and is used in various areas of human activity, especially in military activities, economy and the collection of enterprise organization and management sciences.

The aim of strategic organization diagnosis is ([15], p. 172): „understanding its commercial potential now and in the future. Skills and resources, which, in comparison with the competition, decide about the strengths and weaknesses of the enterprise in the market, are the substance for the potential. Basic areas of strategic diagnosis procedures application are: marketing and product distribution policy, logistics, finance, human resources, technology and production management. IT is the integrating element.

It is purposeful to consider the complex informatization issue in both macro scale, from the perspective of the whole enterprise, and micro scale - evaluation of technical, functional and using quality of systems and application that support particular organizational units. Key requirements towards the IT technology need to be distinguished and the complex informatization plan has to be elaborated in the strategy stage. Tasks connected with a detailed analysis of informational content as well as the implementation technology should be postponed until the system analysis and system design is prepared. Strategy construction stage should be initiated with researching diagnosis. Specification of basic business processes should be performed next. Process knowledge allows to correctly evaluate exploited IT systems, identification of bottlenecks in work organization,

documentation flow and data processing technology.

Basic aims set for the research diagnosis are:

- analysis of basic enterprise management system dysfunctions (e.g. product and service distribution, 
work organization, production, logistics) and indication of proper corrective activities,

- evaluation of proper IT technology - description of realized functions and the use of benchmarking in order to gain the answer for the following question: how far are the currently used IT products fulfill the informational needs of the users?

It is important to point out that the enterprise management diagnosis system should be realized by external specialists. Evaluation formulated by a group of external experts is necessary due to the fact that usually the technical staff and the managerial personnel have a false belief about the unit they are responsible for. Their perspective is loaded with, so called, parental effect, meaning that usually the parent does not see the drawbacks of his or her offspring.

It is necessary to elaborate the architecture of a new IT system, supporting the entity of recording and processing of industrial events, in the strategy phase. Elaborated concept needs to be strictly linked with current technical IT resources. For example, from the perspective of technological factors and cost of planned investment especially significant is the system task division between the centralized architecture and dispersed processing. This decision is connected with the creation of relevant technical infrastructure (local area network or corporate network), selection of particular software tools groups (e.g. database management system, dispersed transaction servicing support) and elaboration of the preliminary application construction rules (e.g. three-layer software construction, with the use of Internet Explorer internet browser as the client application).

It is crucial to emphasize that the lack of defined guidelines in the scope of the IT system architecture, especially the design of the task division between the centralized architecture and dispersed processing, of forecasted load of future applications and normative acts, form the scope of software production, prevents form making an unequivocal decision about the selection of particular database management system and the programming software packages.

Strategy construction stage is closing the elaboration of decision selection criteria of the IT technology and the formulation of general informatization plan for particular industrial object. Initial estimation of economic cost of activities, connected with the realization of set informatization endeavor, is especially significant at this process stage.
Detailed description of planned informatization strategy is beyond the thematic scope of the article. Issues connected with the comparison analysis of methods and techniques of strategic IT technology, organization and strategy realization methodology planning, strategic development plan and evaluation of opportunities and threats of IT services outsourcing is described in the following works: ([8], pp. 125-148, [11], pp. 207-224 and [3], pp. 487-535).

\section{Stage 2 System analysis}

Performance of a complete system analysis of the industrial organization, elaborated due to the implementation of integrated IT system supporting the realization of basic enterprise activities areas, is the next stage of the process.

Basic aim of the complete analysis is the elaboration of source documents flow, input and output data specification and presentation of a consistent concept of enterprise business processes transformation for the needs of the IT system (function, processes and organizational structures reorganization).

The scope of analytical activities should include:

- elaboration of terminology standards and activities documentation rules (key concepts, objects, actors definitions - creation of data dictionary),

- recording and substantial verification of all types of source documents registered in the future IT system,

- elaboration of documentation flow rules, description of particular data fields in source documents and determination of the moment they enter the system,

- description of procedures and algorithms for the processing of elementary data,

- elaboration of information validation and authorization rules,

- determination of the functionality of prepared IT systems, elaboration of deviation protocols, determination of rules, technology, deadlines and cost of claim realization and changes in the standard software,

- detailed description of the structures generated with the reporting system.

System analysis should also include the scope of activities leading to the integration of domain subsystems currently exploited by the enterprise.

It is important to remember about that all independent partial activities (micro analyses), due to their partial nature and focus on problem solving in particular prob- 
lem areas, cannot be the basis for the solutions of technical and functional architecture of the integrated system. Synergy effect does not take place. Fragmentary analyses assumptions are not equal to the complete system analysis of the enterprise, due to information redundancy and not-optimal interfaces and integral relations. Such activities can only be used in temporary solutions.

Stage 3 Creation of technical and system infrastructure

The next stage is the creation of technical and system infrastructure in the mother enterprise, its local production and cooperating plants, research and development, administration and servicing units as well as external partners, component suppliers. Technical infrastructure is defined as: design and installation of LAN local area network, determination of cooperation scope in the corporate WAN network (Internet, Intranet), technical parameter specification of computers used as workstations and servers, selection of operational system environment and database platform.

Formulation of the system platform selection criteria, database management system and the analysis and evaluation of existing solutions, with the inclusion of technical parameters of designed IT system, are the integral elements of the technical implementation preparation process. Technical parameters of the designed informational system, crucial due o the selection of operational system platform, consist of: system architecture (central, dispersed processing) number and informational complexity of registered documents (input) and generated comparisons and reports (output), size of data collections, number and complexity of transactions, number of parallel computer stands.

It is necessary to perform installation and configuration procedures of the integrated IT system before the start of implementation activities. Technological properties of the programming environment inbuilt in the ERP package prevent the practical usage of single-system constellation in the production of the integrated system. It is important to bear in mind that the complete information about data objects, interface objects and industrial processes is stored in the ERP package repository. Thus technical or functional changes introduction is system modules generates immediate changes in the production environment of the processing.

Single-system constellation prevents the system parameterization and functional changes and extensions per- formance - lack of acceptation test phase is equal to experiments on the "living organism" in practice, possible errors can result in the breakdown of exploited production system.

Introduction of double-system constellations is a relatively low-cost, easy to administrate solution. The following can be distinguished:

- System 1 - development and test system

Changes and functional extensions, result of the ERP package specifics adaptation to the requirements of the enterprise (documentation concerning the scope of changes and the methods of their realization is created during the analytical and design works), implemented in test environment and subjected to a series of technical and integration tests.

- System 2 - production system

Introduction of created (modified) data objects, object interfaces and program code modules (processing algorithms) to the production environment, according to the schedule of the project, are the results of the performance of a series of acceptation tests.

In case of large and complex IT projects it is important to introduce the three-system constellation during the implementation process.

- System 3 - training system

Installation of the training system should be performed in a selected segment of the computer network. Training participants perform a series of processing operations and get to know the advanced functions of the package. Mistakes made in the training process do not have an influence on the functioning of the production system.

Stage 4 Construction (implementation) of integrated IT system

The effect of integration activities is the construction (implementation) of the integrated system that fulfills the normative MRP/ERP standards and is based on a homogenous central database for the whole industrial organization, in the scope of independent domain subsystems exploited by the enterprise. Process of formulation of detailed criterion of analysis and evaluation of future systems and IT technologies is dependent on the nature of particular IT endeavor.

It is reasonable to distinguish three main partial elements of the integrated IT system evaluation procedure: standard functionality, technical architecture, flexibility of the system (see Figure 3): 
- standard functionality - set of activities, processing operations, documents (forms, reports, comparisons) available as part of the standard software package, possibility to define business processes of the enterprise without the necessity to interfere with the source code of the application, ergonomic application interface,

- technical architecture of the application software determines the basic features of the IT system, which are: safety, reliability, openness, scalability, interoperability,

- system flexibility - possibility of the system to adapt to the specifics and needs of particular enterprise (set of vision tools dedicated to the construction graphical application elements e.g. collections, reports, dialogue windows, integrated programming environment dedicated to creation, testing and compilation of new modules and functional expansions).

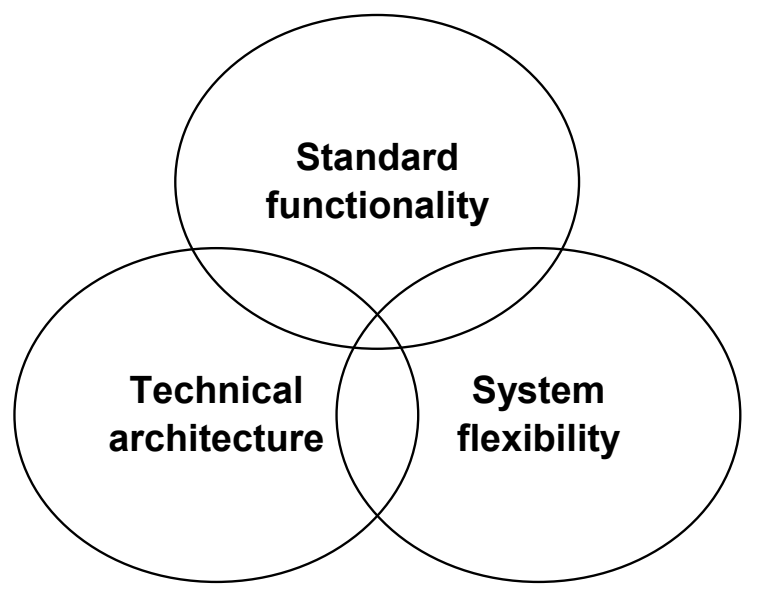

Figure 3. Basic elements of integrated IT system evaluation (source: self study)

Functionality evaluation, experience of the bidder and license cost calculation of particular modules are the first (initial) stage of the system category procedure selection. Afterwards it is necessary to perform detailed evaluation of technological features. Technical architecture determines the basic system features, which are: scalability, openness and flexibility - system vulnera-

\footnotetext{
${ }^{4}$ Scalability - ability of the IT system with an increasing number of users, increasing volume of data collections and expansion of computer network, to function efficiently. The factors that determine system scalability are: architecture (central, dispersed processing), number and complexity of registered documents (input) and generated reports (output), size of data collections, number and complexity of transactions, number of computer workstations.
}

bility for extensions and modifications. Proper evaluation of technical parameters has a major influence on the real (final) cost of implementation.

Implementation of integrated IT system, aimed at introduction of process management in the enterprise, is a suitable moment for the realization of a number of organizational changes. In practice there is a common theory that the implementation of an integrated IT system is a compromise between finished product functionality and the necessity to perform restructuring in the enterprise. This problem is especially important in case of heterogeneous systems. Detailed determination of restructuring plan and formulation of the methodology and implementation activities schedule as well as elaboration of technical and designing solutions, in scope of standard software adaptation to the character and requirements of the enterprise, is possible on the particular focus, putting on the fulfillment of scalability requirement of the integrated system. Selection of proper operational environment, database platform and technological system architecture should assure an effective functioning of the system, regardless of the load.

Data processing process efficiency, expressed in the number of recorded and generated documents, cannot be limited with the software architecture of the system but only with technical parameters of servers and workstations. In other words, integrated system should work efficiently while processing ten thousand invoices and accounting documents per month as well as when prospecting one hundred thousand invoices and accounting documents per month. The speed of the system should be only limited by the possibilities of available equipment.

\section{Summary}

Construction of the integrated IT system allows not only the elimination of data redundancy and significant error reduction (occurring as a result of repetitive introduction of the same data into the system) as well as implementation of different process configuration based on the complete system analysis.

Decision about the selection of a particular ERP IT system is not an easy one. National industrial enterprises, in the light of information globalization, before the selection of particular IT solution should elaborate the strategic enterprise development and informatization plans. 
It is important to determine key requirements and expectations of the final solution at the stage of informatization strategy formulation stage - economic benefits from the implementation of the MRP/ERP system. During the formulation of the requirements it is crucial to have the interest of the whole enterprise in mind, with the exclusion of operational side of currently exploited IT systems (e.g. graphical layout of the reports for the human resources department). User expectations connected with the operational side of the IT system will be processed during the complete system analysis.

The stage of strategic IT development plan should distinguish the strategic systems and select the way of implementation. Therefore the realization of implementation activities based on the IT personnel or ordering part of the works to an external company (outsourcing) is possible. Construction of the system with the use of owned IT resources can be recommended to large enterprises, which ([16], p. 78): have proper knowledge and experience in all areas of system integration, can withstand the considerable cost of long-term global expenses, develop specific informational systems and aim at maintaining the control over the production of strategic applications. Whereas outsourcing is advised to enterprises, which have limited experience in construction and integration of systems and the system itself is not to be a strategic application.

When analyzing the modern trend of integrated system development, it is important to draw one's attention to the software lease method in the Application Service Provision, see ([10], pp. 48-55). Application lease concept is a natural extension of WAN technologies and internet development. In the ASP system the enterprise is granted a $24 \mathrm{~h}$ access to the software that exceeds the purchasing possibilities of the enterprise in the standard set, exploitation fees are relevant to the application usage, software installation issue is limited only

to proper configuration of internet browsers (e.g. Internet Explorer). Archiving of the data is one of the duties of the ERP package provider. Enterprise can gain significant savings through the reduction of employee number. Software outsourcing in the ASP system can be recommended in case of standard implementations.

Considerable reduction of implementation cost is possible in case of standard solutions for typical areas of enterprise activity (e.g. finance and accounting). In case of highly technologically complex solutions e.g. integration of specific domain subsystems with standard modules of the ERP package, it seems that the traditional methods of license and IT services selling will dominate.

The key element of the implementation is proper reconstruction of industrial processes performed to optimize work organization methods and material resources flow. Results of complete system analysis of the industrial organization should answer the questions about the restructuring directions, informational needs and decide about the selection of proper functionality and technological architecture of the ERP package.

It is important to see that the mistakes made in the analysis stage will cumulate and usually be detected during trial tests of particular modules, what usually leads to delays and performance of unpredicted changes.

Evaluation of the compromise degree between functionality and change and modification possibilities as well as the necessity to perform restructuring in the enterprise are especially important in the process of construction (implementation) of complex ERP systems. Selection of proper implementation methods of all extensions in the standard software determines the overall quality and flexibility of the final solution, risk and cost of the endeavor as well as other investments required for the maintenance and modernization of the system. Technical aspect of the implementation is equally crucial (e.g. safety and scalability of the system, data integration and ergonomics of the interface). Summing up, it is necessary to state that the selection of proper enterprise IT process integration implementation methodology and technology decides about the success of the investment.

\section{$7 \quad$ References}

[1] Abramowski K. - Integracja przedsiębiorstwa [in] Infoman, No. 4, 2000, pp. 30.

[2] Bazewicz M. - Metody i techniki reprezentacji wiedzy w projektowaniu systemów. Wyd. Politechniki Wrocławskiej, Wrocław 1994.

[3] Bocij P., Chaffey D., Greasley A., Hickie S. Business Information Systems. Technology Development and Management. Pearson Education, Londyn 1999.

[4] Braa K., Sandahl I. - Approaches to standardization of documents [in] Information and process 
integration in enterprises. Kluwer Academic Press, Boston 1998.

[5] Bues M. - Offene Systeme. Strategien, Konzepte und Techniken für das Informationsmanagement. Springer, Berlin 1994.

[6] Chmielarz W. - Systemy informatyczne wspomagajace zarzadzanie. Aspekt modelowy w budowie systemów. Dom Wydawniczy "Elipsa", Warszawa, 1996.

[7] Flakiewicz W. - Pojęcie informacji $w$ technologii multimedialnej [in] Badania Statutowe SGH, No. 03/S/0018/99, KAE SGH (maszynopis powielony), Warszawa 1999, pp.2-7.

[8] Goliński J., Mrozik S. - Strategiczny plan rozwoju zastosowań informatyki podstawa efektywnego zarzadzania [at] IV Ogólnopolska Konferencja nt. Komunikacja miejska. Efektywność transportu zbiorowego w miastach. Izba Gospodarcza Komunikacji Miejskiej, Łódź 2000, pp. 125-148.

[9] Heng K. - Enterprise modeling within the Framework of Business process reengineering [in] Information and process integration in enterprises. Kluwer Academic Press, Boston 1998.

[10] Kniaź A. - Obietnice wschodzacego rynku [in] PC Kurier, No. 17, 2000.

[11] Krupa T. - Projektowanie strategii informatyzacji [in] Przedsiębiorstwo w procesie globalizacji. WNT, Warszawa 2001, pp. 207-224.

[12] Lasek M. - Modele referencyjne struktur procesowych przedsiębiorstw [in] Studia Informatyki gospodarczej. Integracja i Architektury systemów informatycznych przedsiębiorstw. Wyd. WNE Uniwersytetu Warszawskiego, Warszawa 2000, pp. 209.

[13] Lasek M. - Integracja w przetwarzaniu informacji gospodarczych [in] Informatyka. Wydanie specjalne, No. 1, 1998.

[14] Niedzielska E. - Zintegrowane środowisko zarzadzania jako perspektywiczna platforma użytkowania gospodarczych systemów informacyjnych [in] Business Information Systems '97, Poznań 1997.

[15] Obłój K. - Strategia organizacji. PWE, Warszawa 1998.

[16] Pańkowska M. - Współdziałanie podmiotów rynku produktów i ustug informatycznych. Wyd. Akademii Ekonomicznej, Katowice 1998.

[17] Perreault Y., Vlasic T. - Wdrażajac Baan'a IV. Autorski przewodnik prac przygotowawczych i wdrażania. UCL systemy MRP II S.C., Skierniewice 1998.

[18] Sakai N. - Logical Structure Transformation between SGML documents [in] Information and process integration in enterprises. Kluwer Academic Press, Boston 1998, pp. 183-198.

[19] Wigand R., Picot A., Reichwald R. - Information, Organization and Management. Expanding Markets and Corporate Boundaries. John Wiley \& Sons, New York 1997. 